\title{
El basamento cristalino de los Andes norpatagónicos en Argentina: geocronología e interpretación tectónica
}

\section{Ricardo Varela}

Miguel A.S. Basei

Carlos A. Cingolani

Oswaldo Siga Jr.

Claudia R. Passarelli
Centro de Investigaciones Geológicas (CIG), Universidad Nacional de La Plata (UNLP)-Consejo Nacional de Investigaciones Científicas y Técnicas (CONICET),

Calle 1, No. 644 (1900) La Plata, Argentina

varela@cig.museo.unlp.edu.ar

Centro de Pesquisas Geocronológicas (CPGeo), Instituto de Geociências, Universidade de São Paulo, Cidade Universitaria, Rua do Lago 562 (05508-900) São Paulo, Brasil baseimas@usp.br

Centro de Investigaciones Geológicas (CIG), Universidad Nacional de La Plata (UNLP)-Consejo Nacional de Investigaciones Científicas y Técnicas (CONICET)

Calle 1, No. 644 (1900) La Plata, Argentina

ccingola@cig.museo.unlp.edu.ar

RESUMEN

Se presentan los resultados obtenidos en el estudio isotópico de rocas del basamento ígneo-metamórfico de los Andes expuesto en Argentina, aproximadamente a los $40^{\circ} \mathrm{S}$, en las provincias de Neuquén y Río Negro. Fueron utilizadas metodologías isotópicas, para obtener información sobre la edad de emplazamiento de cuerpos ígneos deformados dúctilmente ( $\mathrm{U}-\mathrm{Pb}$ en circones), tiempo de enfriamiento luego de los procesos ígneos y metamórficos que modelaron a este basamento (K-Ar en micas; U-Pb en titanita) y la historia cortical involucrada (Sm-Nd en roca total). No se obtuvieron edades proterozoicas, como lo sugerían anteriores determinaciones Rb-Sr y K-Ar. Los datos definen en la región dos eventos ígneo metamórficos. El más antiguo, conservado en tonalitas y granitos deformados de los alrededores de San Martín de los Andes, tiene edades U-Pb en circones de 420 a 380 Ma (Devónico) y edades K-Ar en micas de 375 a 310 Ma. El más joven está bien representado en los afloramientos al sur del Río Limay, desde Paso Flores a Río Chico-Cushamen y tiene edades U-Pb en circones de rocas metaígneas en torno a $280 \mathrm{Ma}$ (Pérmico inferior) y edades de enfriamiento en micas próximas a 260-250 Ma. Ambos conjuntos se generaron en ambiente de arco magmático y denotan la acción de dos episodios principales separados por ca. $100 \mathrm{Ma}$, posibles de relacionar con los Movimientos Chánicos y Gondwánicos, respectivamente. Las edades modelo Sm-Nd T $\mathrm{Ma}, \varepsilon N d$ para el momento de cristalización de las rocas de preferencia entre $-3,0$ y $-8,4$ y $\varepsilon \mathrm{Nd}_{(0)}$ preferentemente entre $-6,9$ a -11,9 sugieren reciclado de corteza proterozoica con escasa adición de corteza juvenil durante el Paleozoico.

Palabras claves: Basamento, Edades isotópicas, Andes norpatagónicos, Patagonia, Argentina. 


\begin{abstract}
The Crystalline Basement in the Argentinian North-Patagonian Andes: geochronology and tectonic interpretation. Isotopic data are presented for rocks of the Andean crystalline basement at $40^{\circ} \mathrm{S}$, in Neuquén and Río Negro provinces. The methods used were $\mathrm{U}-\mathrm{Pb}$ in zircon (crystallization ages of plutonic rocks), K-Ar in micas and U$\mathrm{Pb}$ in titanite (metamorphism and cooling ages) and $\mathrm{Sm}-\mathrm{Nd}$ in whole rock (crustal evolution). No Proterozoic ages were obtained as suggested by previous $\mathrm{Rb}-\mathrm{Sr}$ and $\mathrm{K}$-Ar data, and two different igneous-metamorphic events were identified. The older one is Devonian and exposed in San Martín de los Andes region, according to 420-380 Ma zircon ages and 375-310 Ma ages in micas of deformed tonalitic and granitic rocks. The younger one, in rocks cropping out to the south of Limay River region, is revealed by Early Permian zircon ages (about $280 \mathrm{Ma}$ ) and Late Permian cooling ages (260$250 \mathrm{Ma}$ ) of metaigneous rocks. The rocks of both sets were assigned to a magmatic arc environment and correlated respectively with the Chanic orogeny (Devonian; Upper Famatinian Cycle) and Gondwanic Cycle (Upper PaleozoicTriassic). The Sm-Nd $T_{D M}$ model ages, ca.1907-1165 Ma, $\varepsilon N d$ for the crystallization age of the rocks ca. $-3,0$ and $-8,4$ and $\varepsilon \mathrm{Nd}_{(0)}$ ca. $-6,9-11,9$ suggest reworking of continental proterozoic crust with minor addition of juvenile magmas from the mantle during the Paleozoic.
\end{abstract}

Key words: Basement, Isotopic ages. North-Patagonian Andes, Patagonia, Argentine.

\title{
INTRODUCCIÓN
}

En el noroeste patagónico argentino el Basamento Cristalino soporta sucesiones volcano sedimentarias y eventualmente es el encajonante de rocas plutónicas, en ambos casos del Triásico Superior o de menor antigüedad (Fig. 1).

Los afloramientos de Basamento son parte del Macizo Norpatagónico y de la Cordillera Norpatagónica y están formados por dos componentes mayores. El más antiguo de ellos consiste en ectinitas y rocas metaígneas y el más joven está formado por rocas plutónicas no deformadas y menor proporción de rocas volcánicas y subvolcánicas.

El segundo de los componentes nombrados tiene las mejores exposiciones en el borde norte del Macizo Norpatagónico, al este de los 69³0' . El estudio geológico, geoquímico y radiométrico de sus rocas fue realizado en el área tipo de $\mathrm{La}$ Esperanza por Llambías y Rapela (1984), Rapela y Llambías (1985) y Pankhurst et al. (1992). De acuerdo con lo informado por dichos autores dominan ampliamente las rocas ígneas, con relictos de ectinitas de las rocas de caja. El ordenamiento estratigráfico considera de más antiguo a más moderno al Complejo plutónico La Esperanza, principalmente granodioritas y granitos, y al Complejo plutónico volcánico Dos Lomas, formado por dacitas, riolitas y leucogranitos. Las edades $\mathrm{Rb}$-Sr por isócronas de rocas totales son de $258 \pm 15$
Ma y 259₫16 Ma (Pérmico Inferior tardío-Pérmico Superior) para el Complejo La Esperanza y de 239 \pm 4 Ma (Triásico inferior) para el Complejo plutónico-volcánico Dos Lomas.

El componente de basamento de mayor antigüedad relativa cobra importancia al oeste de los 69³0' y la asociación de ectinitas y rocas metaígneas aflora en las proximidades de Cushamen, Río Chico, Río Limay, Sañicó, San Martín de los Andes y Bariloche. Las ectinitas se han reunido en la Formación Cushamen en el Macizo Norpatagónico y en la Formación Colohuincul en la Cordillera Norpatagónica. Las rocas metaígneas incluyen a la Tonalita del Platero y Formación Mamil Choique (en el Macizo Norpatagónico) y Formación Huechulafquén y Tonalita San Martín de los Andes en la Cordillera Norpatagónica (Volkheimer, 1964; Ravazzoli y Sesana, 1977; Turner, 1973; Dalla Salda et al., 1991a). Estas rocas metamórficas, tanto de protolitos sedimentarios como ígneos, son el objeto de la presente contribución.

Hasta hace pocos años este basamento fue considerado como Proterozoico y Paleozoico inferior (Servicio Geológico Minero Argentino, 1997), sobre la base de correlaciones regionales y edades radiométricas obtenidas por los métodos $\mathrm{K}-\mathrm{Ar}$ y $\mathrm{Rb}$-Sr. Pero cabe señalar que sólo puede asegurarse que es anterior al Triásico Superior (ca. 230 


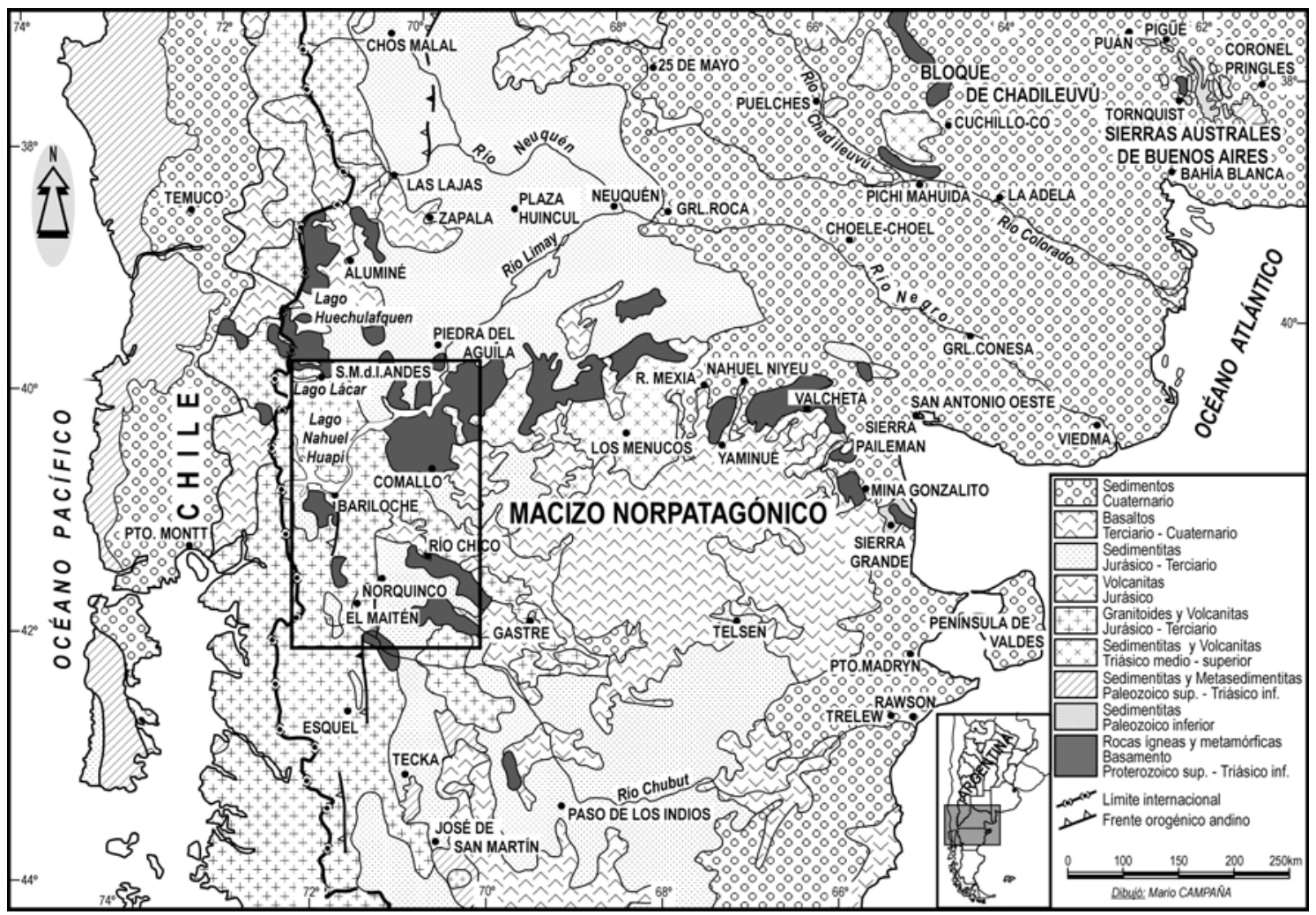

FIG. 1. Mapa geológico entre los 38 y $44^{\circ} \mathrm{SS}$, mostrando los afloramientos mayores de basamento ígneo metamórfico y en recuadro el área estudiada. Simplificado del Servicio Nacional de Geología y Minería (1982) y Servicio Geológico Minero Argentino (1997).

$\mathrm{Ma}$ ), atendiendo al contenido paleoflorístico (Kokogian et al., 1999 y referencias en ese trabajo) y edad isotópica de ignimbritas (Rapela et al., 1996) de la cobertura volcano-sedimentaria que se le sobrepone. También contribuye a indicar edades mínimas la datación isotópica de plutones no deformados que cortan las estructuras metamórficas, los más antiguos de los cuales son del Pérmico superior (ca. 260 Ma; Pankhurst et al., 1992).

La datación isotópica de las ectinitas y rocas metaígneas del basamento de esta región se ha intentado desde hace varias décadas. Los primeros resultados se obtuvieron por el método K-Ar (edades de enfriamiento) y luego se agregaron datos $\mathrm{Rb}-\mathrm{Sr}$ (errorcronas), aunque la compleja historia tectono térmica ha limitado su utilidad y algunas edades carecen de significado geológico. En los últimos años se ha aplicado la datación U-Pb convencional, cuyos resultados son más confiables para el conocimiento de edades de cristalización de rocas metaígneas, habiéndose obtenido valores que difieren considerablemente de los aportados por los otros métodos mencionados. De acuerdo con esto, es necesaria una revisión de la asignación temporal de estas unidades litológicas y modificar algunos conceptos sobre la evolución geológica de la región.

En la presente contribución se dan a conocer nuevas edades radiométricas por los métodos $\mathrm{K}$ $\mathrm{Ar}, \mathrm{U}-\mathrm{Pb}$ y Sm-Nd, resultantes de un Proyecto de Cooperación Internacional entre el CONICET (Argentina) y el CNPq (Brasil). La mayor parte de ellas son inéditas, aunque algunos resultados parciales adelantados en reuniones de la especialidad, son aquí reconsiderados a la luz del conjunto obtenido. 


\section{ANTECEDENTES Y DESCRIPCIÓN DE LAS UNIDADES ESTUDIADAS}

Las ectinitas y rocas metaígneas del basamento tienen buenas exposiciones en las proximidades de Cushamen, Río Chico, Río Limay entre Sañicó y Clemente Onelli, San Martín de los Andes y Bariloche (Fig. 2).

En Cushamen se denominó Formación Cushamen a una sucesión de micacitas, filitas cuarzosas, metacuarcitas y migmatitas y Tonalita del Platero a tonalitas biotíticas y hornblendíferas intrusivas en los metasedimentos (Volkheimer, 1964; Volkheimer y Lage, 1981). Márquez et al. (2002) señalan que el complejo ígneo metamórfico está integrado por metasedimentitas y rocas eruptivas con polideformaciones dúctiles. Indicaron un metamorfismo de grado medio (parte alta de la facies de anfibolita), sobrepuesto por otro de grado medio-bajo (facies de esquistos verdes, zona de la biotita). Entre las rocas ígneas que evolucionaron en conjunto con los metasedimentos, reconocieron varias generaciones de pegmatitas y diques de microgranito, diques de granito alcalino foliado y stocks de tonalita y leucogranito. Las edades por isócronas $\mathrm{Rb}-\mathrm{Sr}$ roca total en esquistos, metagrauvacas y metacuarcitas, comunicadas por Ostera et al. (2001), son de $362 \pm 10 \mathrm{Ma}$ y $371 \pm 33 \mathrm{Ma}$, e indicarían un evento metamórfico en el Devónico inferior-medio. La edad K-Ar en muscovita de un granito leucocrático de muscovita-granate, foliado y emplazado en cuerpos tabulares entre esquistos micáceos, es de 282 $\pm 6 \mathrm{Ma}$, Pérmico inferior, considerada una edad mínima de cristalización (Duhart et al. , 2002).

En Río Chico el basamento fue estudiado por Ravazzoli y Sesana (1977). Un conjunto de esquistos micáceos, metacuarcitas y migmatitas fue asignado, por similitud litológica, a la Formación Cushamen. Para las rocas plutónicas (granodioritas, tonalitas y granitos) crearon la Formación Mamil Choique. Posteriormente, Dalla Salda et al. (1994) reunieron con el nombre de Complejo Río Chico a una unidad metamórfica (Metamorfita Cushamen) y a una suite granítica de dimensiones batolíticas (Granitoides Mamil Choique). El pasaje entre ambas unidades se hace a través de angostas zonas de migmatitas. Los Granitoides Mamil Choique fueron descritos como granodioritas y monzogranitos con biotita y muscovita, de coloración gris y grano medio a grueso. Tienen una esquistosidad bien definida, de orientación similar a la de las ectinitas de la Formación Cushamen y contienen xenolitos de ellas. Cagnoni et al. (1997) de acuerdo a datos químicos de los metasedimentos, interpretaron un ambiente tectónico de antearco. Cerredo y López de Luchi (1999) comunicaron la intercalación de rocas metavolcánicas entre los metasedimentos. Posteriormente, López de Luchi et al. (2002) mediante geoquímica de los metasedimentos de la Formación Cushamen y de sus intercalaciones volcánicas, interpretaron la depositación en margen continental activo, contemporánea y adyacente a volcanismo de arco magmático.

Para las rocas metamórficas de la Formación Cushamen en Río Chico, la edad Rb-Sr obtenida por Linares et al. (1997) es de $707 \pm 18 \mathrm{Ma}$. Las edades radiométricas de los granitoides Mamil Choique provienen de isócronas $\mathrm{Rb}-\mathrm{Sr}$ de $439 \pm 10$ Ma (Dalla Salda et al., 1994), 313 \pm 24 (Linares et al.,

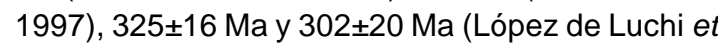
al., 1999). Las edades K-Ar disponibles están en torno a 300 Ma (Ravazzoli y Sesana, 1977; Linares et al., 1997; López de Luchi et al., 1999; Duhart et al., 2002).

La zona Río Limay-Sañicó es la que expone los mayores afloramientos del basamento estudiado, a lo largo de los bajos topográficos de los ríos Limay y Collon Curá. Hay detallada descripción en los trabajos de Galli (1969) y Nullo (1979). Al norte del Río Limay, Galli (1969) describió poca participación de micacitas y rocas cuarcíticas, dominando las migmatitas y las rocas intrusivas de composición granodiorítica y marcada esquistosidad. Al sur del Río Limay, Nullo (1979) destacó la escasa presencia de esquistos (Formación Cushamen), y la abundancia de esquistos inyectados, migmatitas, granodioritas y granitos (Formación Mamil Choique).

Son numerosas las edades radiométricas comunicadas para rocas de esta zona, la mayoría por los métodos Rb-Sr y K-Ar. Linares et al. (1988) presentaron isócronas de referencia $\mathrm{Rb}-\mathrm{Sr}$, con edades de $1190 \pm 16$ Ma y $615 \pm 26$ Ma para rocas metamórficas, de 480 \pm 10 Ma para migmatitas y de $390 \pm 15$ Ma y $280 \pm 5$ Ma para granitos. Varela et al. (1991) obtuvieron en migmatitas una isócrona Rb$\mathrm{Sr}$ de $489 \pm 27 \mathrm{Ma}$. Por el método U-Pb se tiene edades sobre circones de rocas tonalíticas deformadas dúctilmente, comunicadas por Varela et al. (1999) para afloramientos de Paso Flores (292 \pm 9 


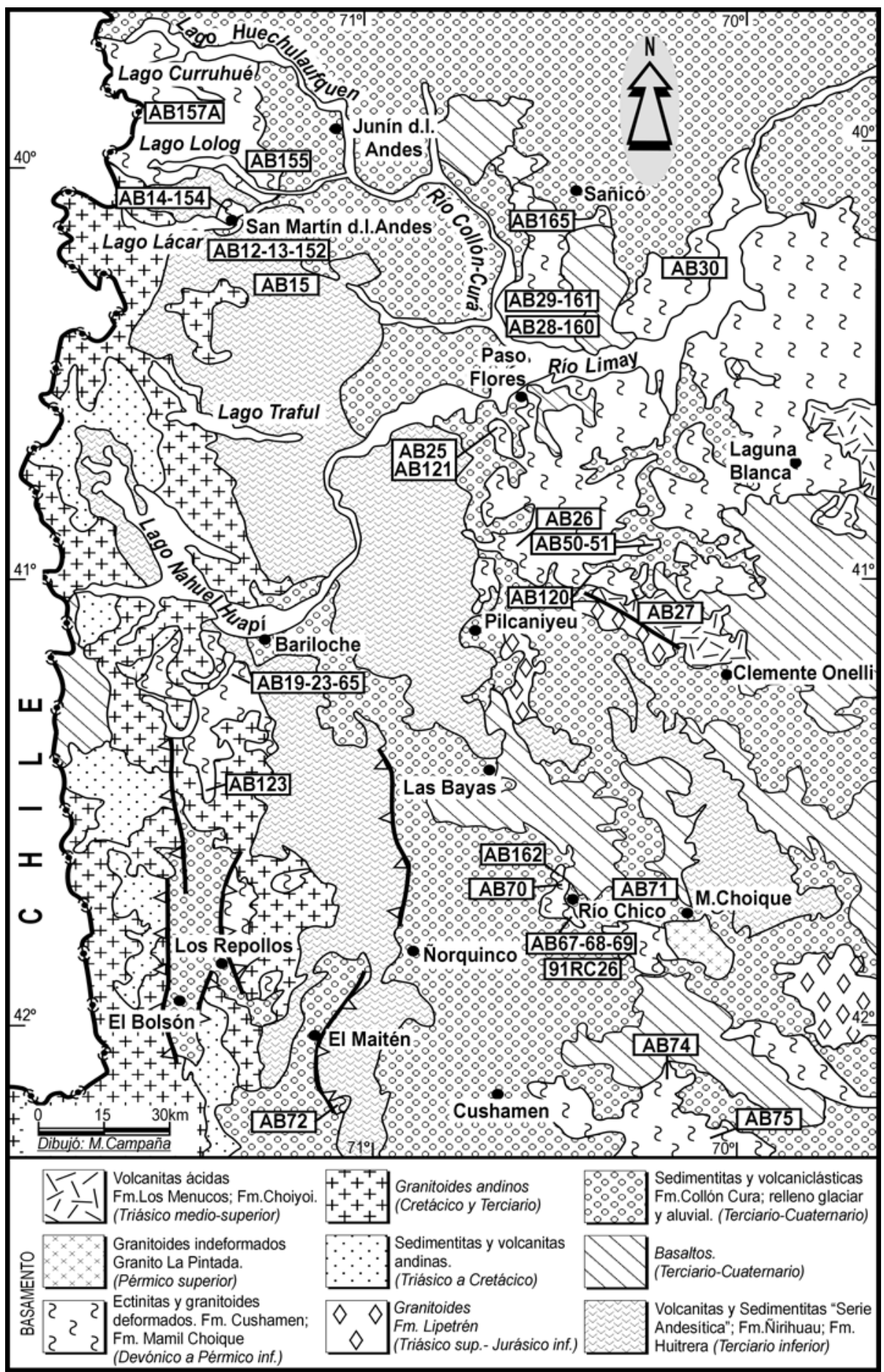

FIG. 2. Mapa geológico del área estudiada, indicando la ubicación de las muestras datadas. Simplificado de la Dirección Nacional del Servicio Geológico (1994); Galli (1969) y Turner (1973). 
Ma), Loma Miranda (269 $\pm 13 \mathrm{Ma})$ y Comallo (334 $\pm 28 \mathrm{Ma})$.

Para la zona San Martín de los Andes, Turner (1973) estableció que son reducidos los afloramientos de esquistos, filitas cuarzosas y cuarcitas, conjunto al que denominó Formación Colohuincul. Contrariamente, cubren gran superficie los afloramientos de granitos migmáticos y migmatitas, de composición dominante granodiorítica, para los que creó la Formación Huechulafquen. Dalla Salda et al. (1991 a) estudiaron este basamento en los alrededores del Lago Lácar y diferenciaron una unidad metamórfica integrada con gneises y migmatitas (Complejo Colohuincul), intrusivos foliados (Tonalita San Martín de los Andes) e intrusivos macizos (Granodiorita Lago Lácar). Mediante isócronas $\mathrm{Rb}-\mathrm{Sr}$ en roca total comunicaron edades de $860 \pm 23 \mathrm{Ma}, 620 \pm 30 \mathrm{Ma}$ y $555 \pm 20 \mathrm{Ma}$, respectivamente. También se tiene la edad $\mathrm{Rb}-\mathrm{Sr}$ de $714 \pm 10 \mathrm{Ma}$, obtenida por Parica (1986) para rocas de la Formación Colohuincul. Finalmente, cabe mencionar las edades obtenidas por Lucassen et al. (2004) en migmatita de San Martín de los Andes (isocróna $\mathrm{Rb}-\mathrm{Sr}$ roca total-minerales, $368 \pm$ $9 \mathrm{Ma}$ ) y en metasedimentos calcosilicáticos del río Collon Curá (U-Pb en titanita, $375 \pm 15$ Ma y $380 \pm 2$ $\mathrm{Ma}$ ).

En la zona al sur de Bariloche, rocas de basamento cristalino fueron reconocidas por Feruglio (1947). La descripción de Dalla Salda et al. (1991 b) menciona esquistos con biotita, esquistos con hornblenda, esquistos con granate, cuarcitas, gneises tonalíticos, gneises calcosilicáticos, cuarcitas y anfibolitas. Una isócrona $\mathrm{Rb}-\mathrm{Sr}$ roca total elaborada con gneis sillimanítico y tonalitas dio una edad de $727 \pm 48$ Ma y edades K-Ar en anfíbola de anfibolitas fueron de 330-350 Ma. Una determinación U-Pb fue realizada por Basei et al. (1999) en circones de anfibolita, con una edad de $346 \pm 4 \mathrm{Ma}$.

\section{MÉTODOS}

Los análisis isotópicos fueron realizados en el Centro de Pesquisas Geocronológicas (CPGeo, San Pablo). Las técnicas seguidas fueron descritas en Amaral et al. (1966) para el método K-Ar, Basei et al. (1995) para el método U-Pb y Sato et al. (1995) para el método Sm-Nd. Las constantes de desintegración utilizadas son las recomendadas por Steiger y Jäger (1977). Para el método Sm-Nd se procesaron rocas totales y la interpretación de resultados se basó mayormente en el modelo de una sola etapa de DePaolo (1981). La preparación de concentrados de minerales para el método $\mathrm{U}-\mathrm{Pb}$ fue, en parte, realizada en el Centro de Investigaciones Geológicas (CIG, La Plata), incluyendo trituración, tamizado, elutriación y separación elec- tromagnética (Frantz). En el CPGeo se utilizó tabla vibratoria y líquidos pesados, se obtuvieron fracciones magnéticas ('split') y se seleccionaron bajo microscopio cristales para los análisis isotópicos. No se efectuaron estudios sistemáticos de catodoluminicencia sobre cristales de circón de las fracciones analizadas, pero se cuenta con dicha información para algunas fracciones representativas de los conjuntos rocosos estudiados. Para el cálculo de edades y confección de diagramas Tera-Wasserburg, fue utilizado el programa Isoplot (Ludwig, 2002), dando preferencia a las medias ponderadas de las edades ${ }^{206} \mathrm{~Pb} /{ }^{238} \mathrm{U}$. La escala de tiempo utilizada es la de Gradstein y Ogg (1996).

\section{RESULTADOS}

En ectinitas asignables a la Formación Cushamen se realizaron dataciones $\mathrm{K}$-Ar en concentrados de biotita y muscovita. En granitoides deformados y migmatitas de las Formaciones Mamil Choique y Huechulafquén/Tonalita San Martín de los Andes, se centró la aplicación del método U-Pb en circones (en una muestra también en titanita), junto a determinaciones $\mathrm{K}-\mathrm{Ar}$ en mica o anfíbola y Sm-Nd en roca total. 


\section{MÉTODO K-Ar (TABLA 1)}

En la zona Río Chico las edades de biotita de esquistos de la Formación Cushamen (AB67, AB68) son de aproximadamente $180 \mathrm{Ma}$, poco más antiguas que la edad de biotita de un pórfido granodiorítico que los intruye (AB69; $174 \mathrm{Ma})$. En la zona Río Limay, se obtuvo una edad de 254 Ma en muscovita de micaesquistos aflorantes al sur del río Limay (AB26), y otra de 322 Ma (AB29) en biotita de un esquisto de Ruta 237, al norte del río Limay.

En rocas asignadas a la Formación Mamil Choique se dataron minerales de las zonas Río Chico y Río Limay. En la primera, concentrados de biotita y de anfibola de granodiorita y tonalita (AB70, $A B 71, A B 74, A B 75)$ tienen edades entre 250 y 275 Ma. En la zona Río Limay, en los concentrados de biotita de granodiorita de Comallo (AB27) y gneis tonalítico de Paso Flores (AB25) se obtuvieron valores próximos a $260 \mathrm{Ma}$, y resultó apreciablemente mayor la edad de biotita de un granito aflorante en Ruta 237 próximo al río Collon Curá (AB28, 308 $\mathrm{Ma}$ ). Finalmente, en muscovita y biotita de granitos aplíticos y pegmatíticos no deformados, que en Cerro Yuncón y Loma Miranda intruyen a los granitoides Mamil Choique (AB30, AB50, AB51) se obtuvieron edades entre 235 Ma y $244 \mathrm{Ma}$.

En la zona San Martín de los Andes, son próximas a $370 \mathrm{Ma}$ las edades obtenidas en biotita de migmatitas de la Formación Huechulafquén aflorantes en Lago Curruhue Grande y Lago Lolog (AB155, $A B 157)$. Fueron similares los valores obtenidos en biotita y anfibola de tonalitas de los alrededores de San Martín de los Andes (Tonalita San Martín de los Andes, AB12, AB14, AB154), entre 376 Ma y 436 Ma. Por último, en biotita de una granodiorita no deformada del empalme de camino a Lago Meliquina (AB15), se obtuvo una edad de $172 \mathrm{Ma}$.

En la zona Bariloche las edades obtenidas en muscovita de esquistos son de aproximadamente $200 \mathrm{Ma}, \mathrm{y}$ la de biotita de una granodiorita intrusiva en ellos es de $140 \mathrm{Ma}$.

\section{MÉTODO U-Pb (TABLA 2)}

De la zona Río Chico se analizaron circones de tres rocas, incluyendo una tonalita deformada próxima al túnel ferroviario (AB70), una muestra representativa de la Granodiorita Mamil Choique del camino Río Chico-Mamil Choique (AB71) y leucogranito de venas deformadas junto a esquistos de la Formación Cushamen en el perfil de Cañadón Chacay Huarruca (AB162 B).

Las imágenes bajo catodoluminicencia (AB 70 y $A B$ 71) muestran predominio de cristales prismáticos, con zoneamiento magmático bien evidente, sin núcleos heredados y con pequeños sobrecrecimientos atribuibles al metamorfismo que afecta a las rocas. Las edades obtenidas son, respectivamente, de $286 \pm 13 \mathrm{Ma}, 272,4 \pm 2,2 \mathrm{Ma}$ y $302 \pm 39 \mathrm{Ma}$ (Fig. 3a, b, c).

De la zona Río Limay se seleccionaron muestras de los afloramientos de Paso Flores, Loma Miranda, Comallo, Ruta 237 al norte del Río Collon Curá y del suroeste de Sañicó.

Al sur del Río Limay, se obtuvo con fracciones de circón de un gneis tonalítico de Paso Flores (AB121) una edad de 273,1 $\pm 9,5$ Ma (Fig. 3d). En cuanto a los circones de una tonalita de Loma Miranda (AB120), cuatro fracciones definieron una edad de $279 \pm 18 \mathrm{Ma}$ (Fig. 3e). Por último, una granodiorita de las proximidades de Comallo (AB27), proveyó mediante la media de las edades de tres fracciones de circón una edad de 281×17 Ma (Fig. 3f).

De las rocas de los afloramientos cercanos al río Collon Curá y Ruta 237, se separaron fracciones de circones de un granito foliado (AB160 A), intrusivo en esquistos con biotita y granate, con las que se

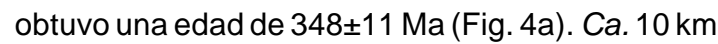
al norte por la Ruta 237, esquistos, migmatitas y granitos son cortados por venas de leucogranito con granate (AB161 A), deformadas y de un espesor de hasta $50 \mathrm{~cm}$. Fracciones de circón de las últimas dieron una edad de 386,6×5,4 Ma (Fig. 4b).

En los afloramientos al suroeste de Sañicó se analizaron fracciones de circón de un ortogneis tonalítico (AB165 A), litología que localmente compone la casi totalidad de afloramientos, y fracciones de circón y de titanita de una metadiorita (AB165 B), variedad litológica minoritaria que forma cuerpos de aproximadamente $0,5 \mathrm{~m}$ dentro de la roca tonalítica. Bajo catodoluminicencia, los circones de la muestra AB 165 A muestran muy diversa tipología, con algunos granos completamente redondeados $y$ otros prismáticos con aristas bien definidas. Muchos cristales presentan núcleos heredados, con evidente sobrecrecimiento periférico. Es un conjunto muy heterogéneo, que justifica la dispersión de las fracciones analizadas en el diagrama concordia 


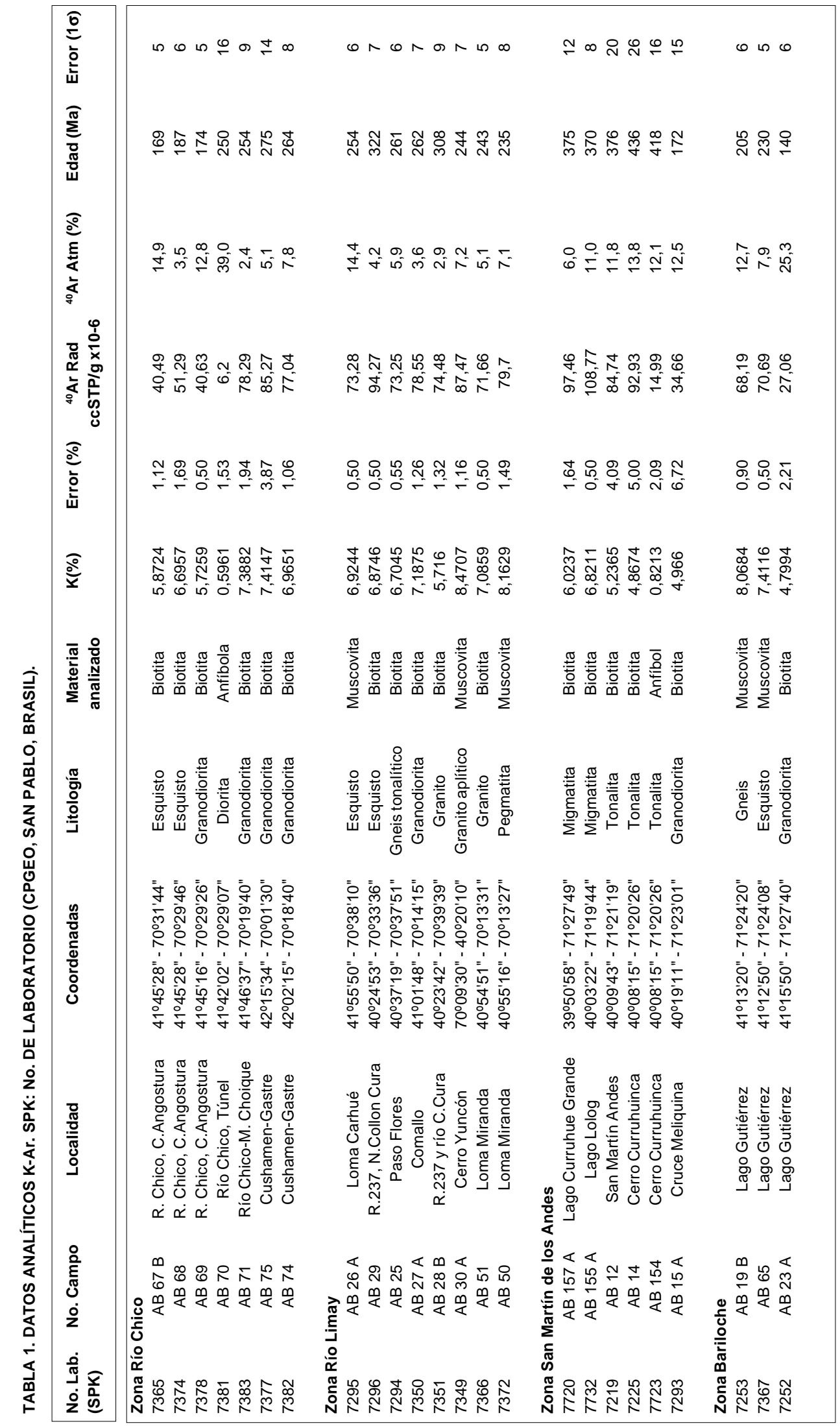




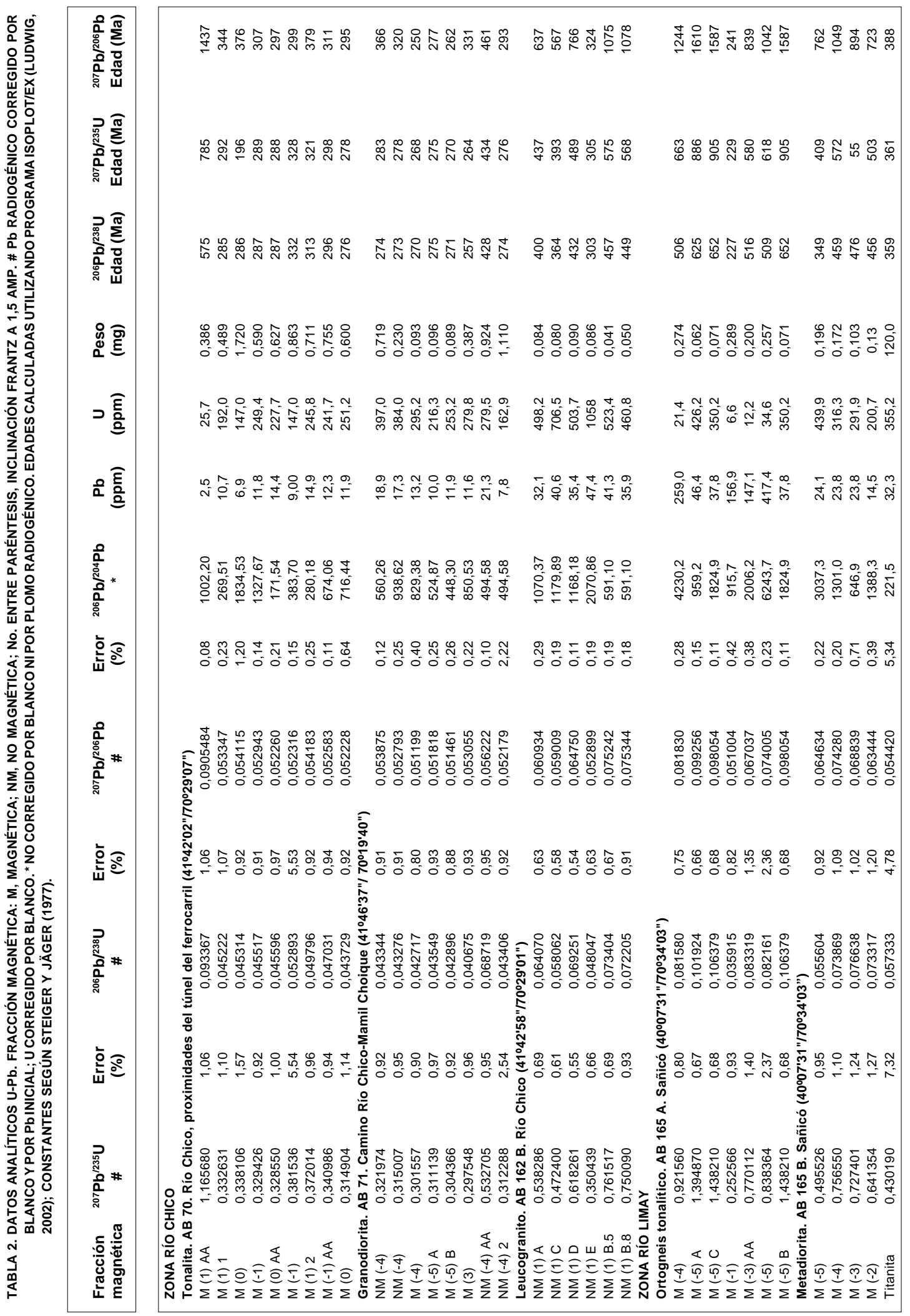




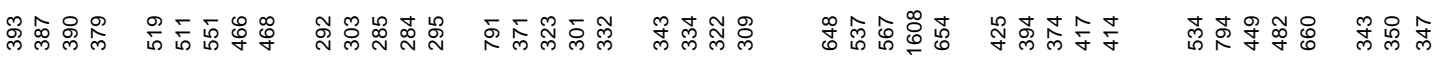

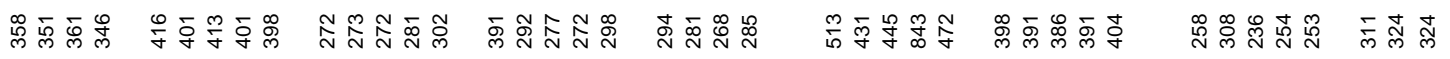

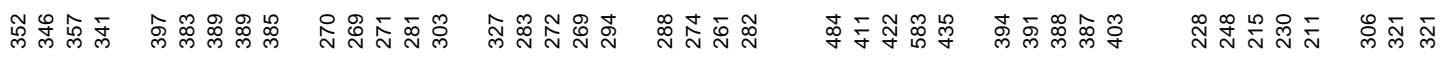

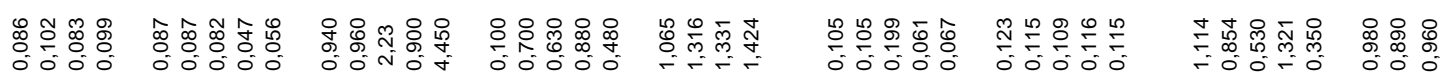

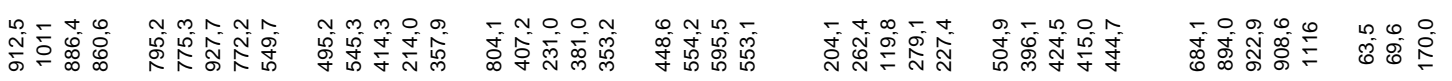

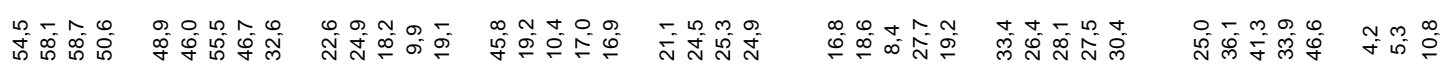

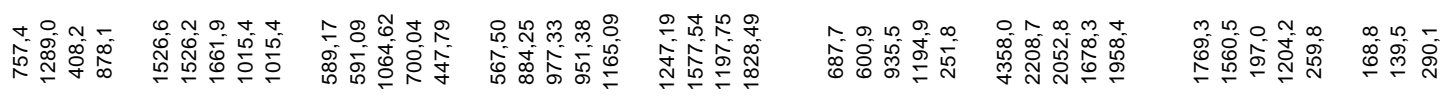

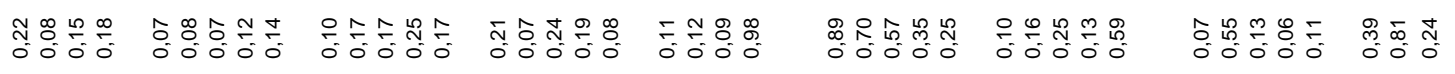

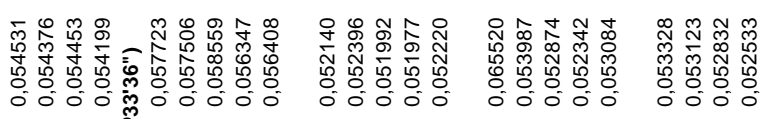
: 空

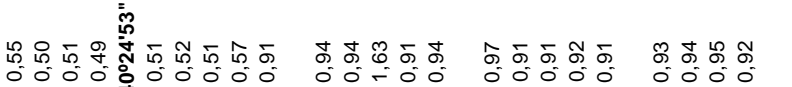

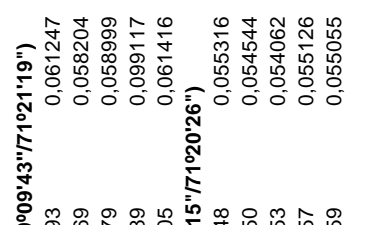

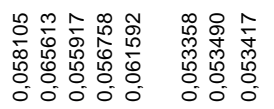
言

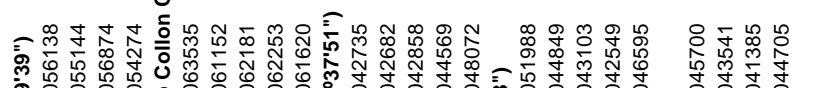

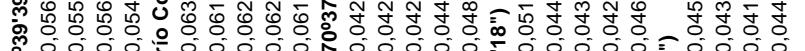

$$
\text { 嘀 }
$$

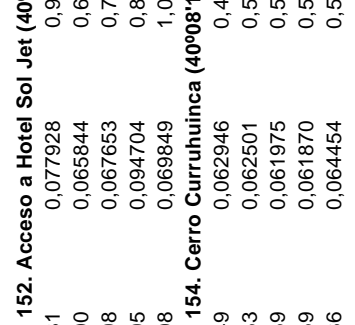

옹영형영영 옹옹영
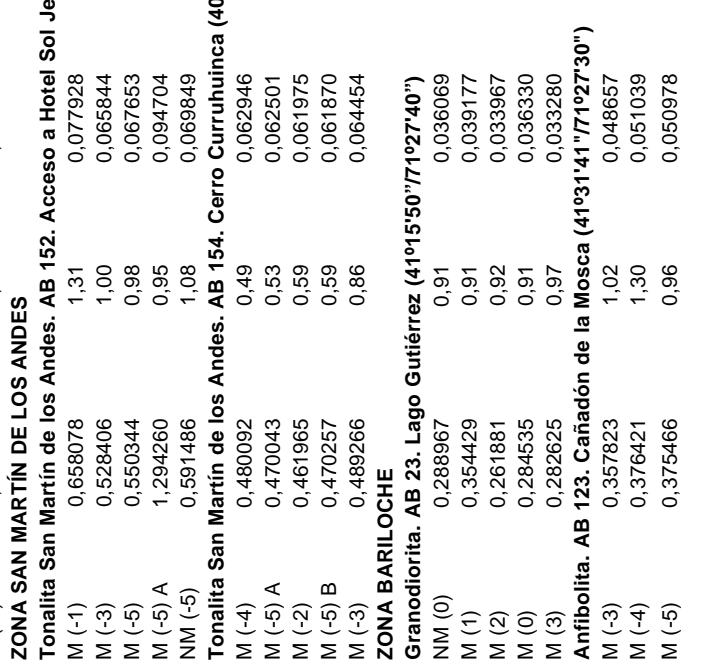

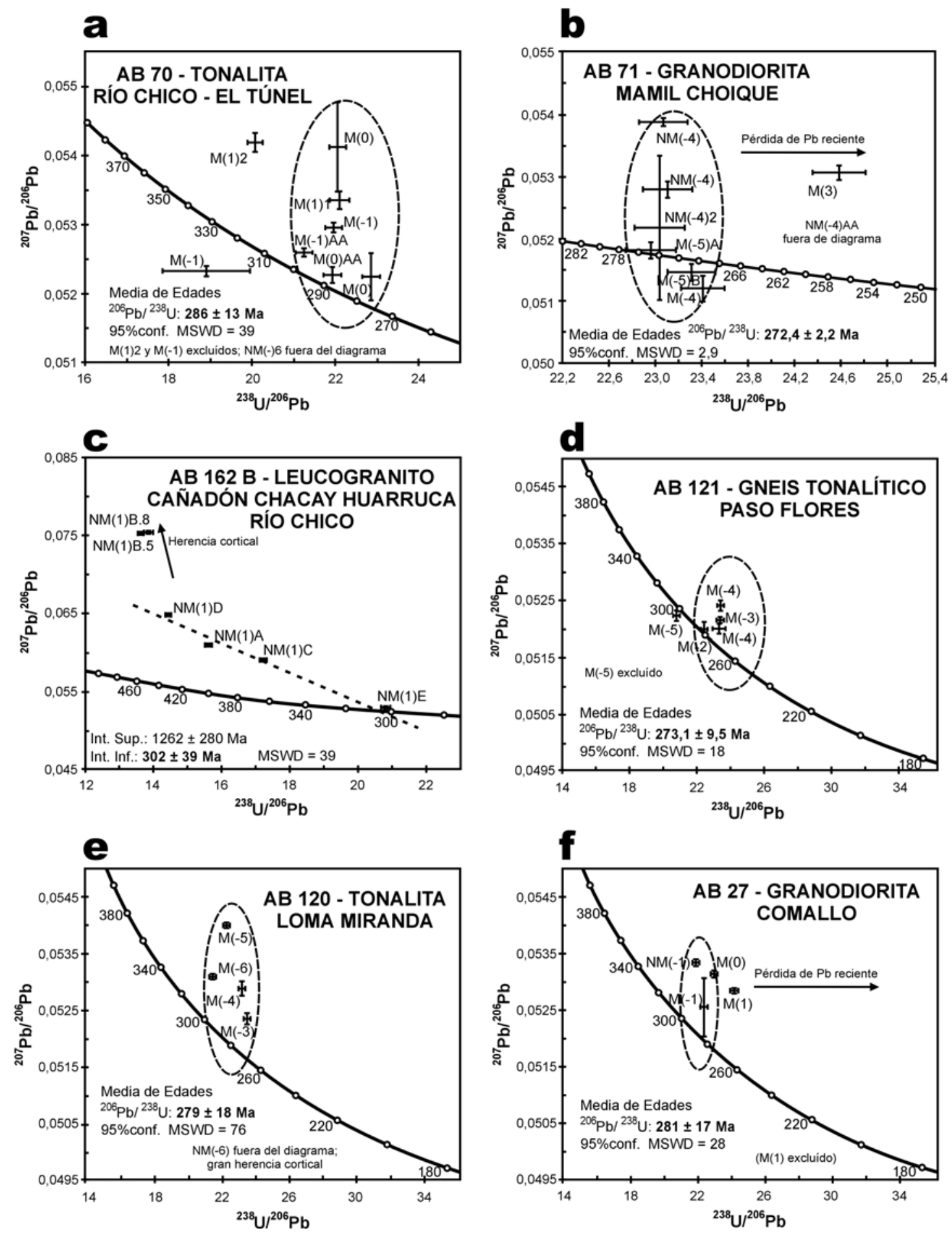

FIG. 3. Diagramas U-Pb Tera-Wasserburg (Ludwig, 2002) para circones de muestras al sur del Río Limay. M(0), NM(-4), etc., identifican las fracciones analizadas. Ubicación en la figura 2 y datos analíticos en la tabla 2. 

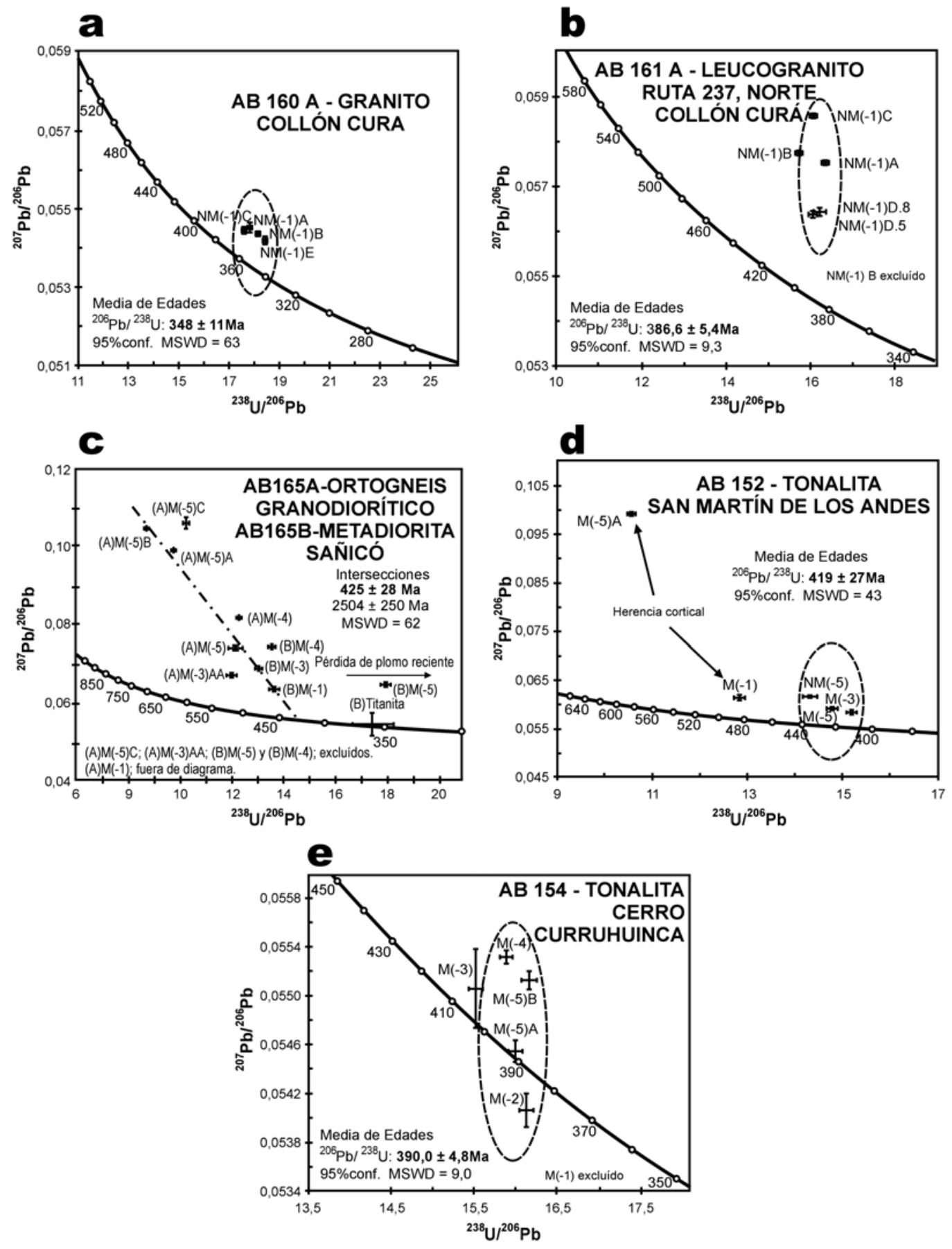

FIG. 4. Diagramas U-Pb Tera-Wasserburg (Ludwig, 2002) para circones y titanita de muestras al norte del río Limay. NM(-1); M(-5)A, etc., identifican las fracciones analizadas. Ubicación en la figura 2 y datos analíticos en la tabla 2. 
correspondiente. Con los circones, se obtuvo una edad de $425 \pm 28$ Ma y el concentrado de titanita es prácticamente concordante en el diagrama concordia y define una edad próxima a $360 \mathrm{Ma}$ (Fig. 4c).

De los afloramientos de basamento de la zona San Martín de los Andes se dataron dos muestras de la Tonalita San Martín de los Andes (AB152 y $A B 154)$. Los circones de una de ellas ( $A B$ 152) muestran bajo catodoluminicencia formas prismáticas sin núcleos heredados y con moderado sobrecrecimiento periférico. Las edades obtenidas fueron de $419 \pm 27 \mathrm{Ma}$ y $390,0 \pm 4,8 \mathrm{Ma}$, respectivamente (Fig. 4d, e).

De rocas de la zona Bariloche, mediante el análisis de tres fracciones de circón se obtuvo una edad de $320,7 \pm 2,1 \mathrm{Ma}$ (Fig. 5a) para una muestra de anfibolita (AB123) de Cañadón de la Mosca. Finalmente, se analizaron cinco fracciones de circón de una granodiorita de Lago Gutiérrez (AB23), intrusiva en los micaesquistos de basamento, que proveyeron una edad de 226 \pm 17 Ma (Fig. 5b).

MÉTODO Sm-Nd (TABLA 3)

Casi en su totalidad las rocas analizadas son rocas ígneas o rocas metamórficas provenientes de protolitos ígneos y en un caso (AB157A) se trata de una migmatita. Los análisis fueron efectuados sobre roca total, utilizando mayormente el modelo de una sola etapa para el cálculo de edades $T_{D M}$ (DePaolo, 1981). De acuerdo con ello se rechazaron aquellas muestras con valores de relación isotópica ${ }^{147} \mathrm{Sm} /{ }^{144} \mathrm{Nd}$ alejadas del rango $0,088-0,125$, típico de productos diferenciados del manto a corteza continental en una única etapa (Cordani y Sato, 1999). Solamente en una muestra (91RC26) se utilizó el modelo de doble etapa (DePaolo et al., 1991), aunque cabe consignar que hay escasa diferencia con los valores obtenidos con el modelo de una sola etapa.

Las edades modelo $T_{D M}$ obtenidas cubren el lapso entre 1165 Ma y 1907 Ma, apreciándose una mayor frecuencia entre $1268 \mathrm{Ma}$ y $1387 \mathrm{Ma}$ (7 de un total de 11 determinaciones). Se apartan significativamente solo las edades obtenidas en dos muestras del oeste de Sañicó, con 1567 Ma y 1907 Ma. Los valores para el momento de cristalización de estos granitoides, $\varepsilon \mathrm{Nd}_{(\mathrm{T} 1)}$, mayoritariamente fluctúan entre $-3,0$ y $-8,4$ y los $\varepsilon \mathrm{Nd}_{(0)}$ lo hacen mayoritariamente entre $-6,9$ y $-11,9$.
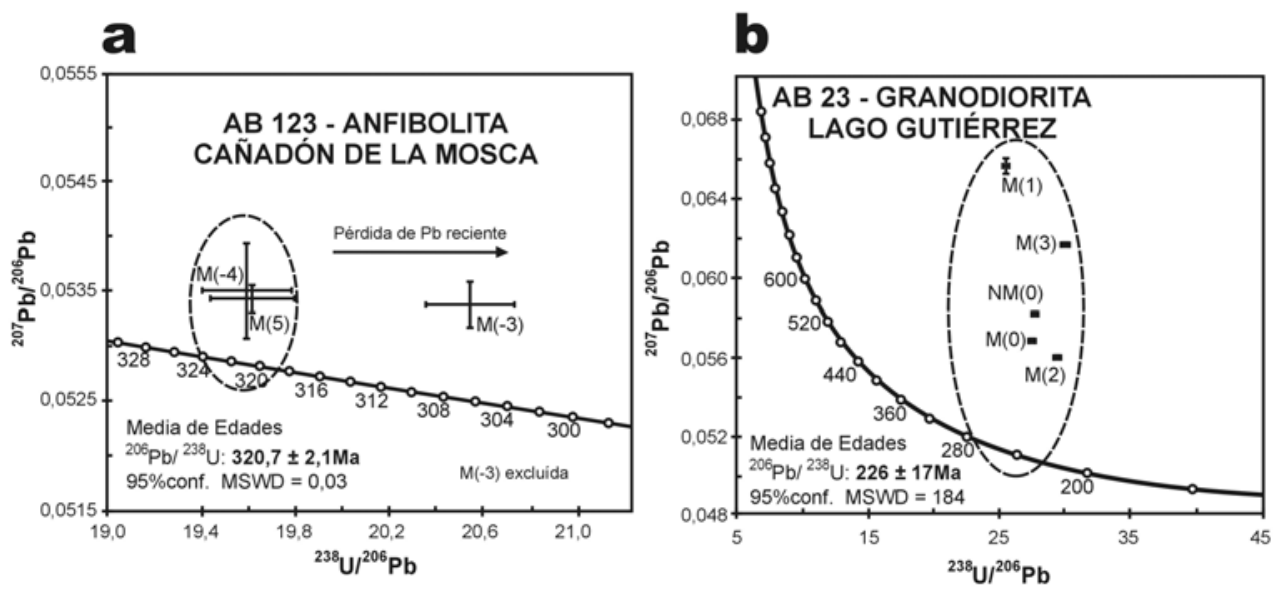

FIG. 5. Diagramas U-Pb Tera-Wasserburg (Ludwig, 2002) para circones de muestras próximas a Bariloche. M(-4), NM(0), etc., identifican las fracciones analizadas. Ubicación en la figura 2 y datos analíticos en la tabla 2. 


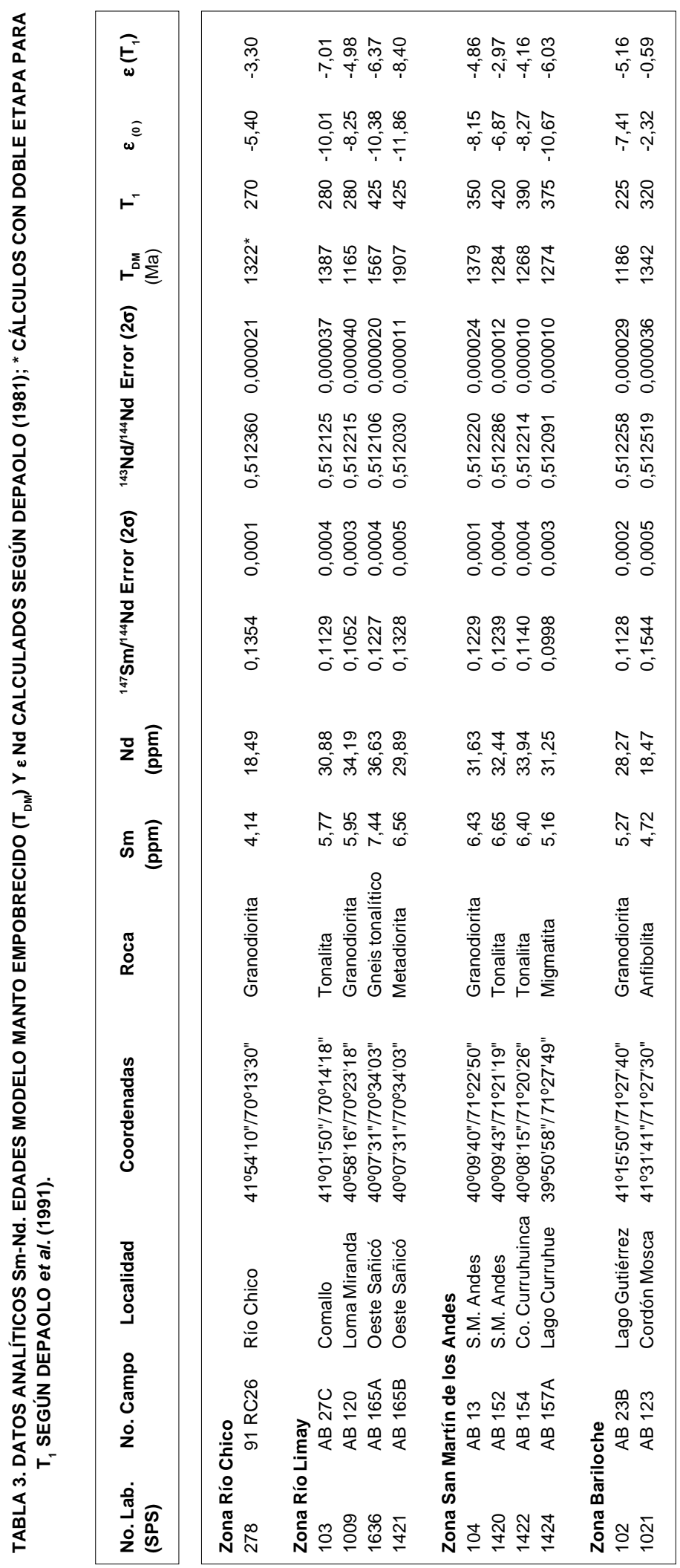




\section{INTERPRETACIÓN TECTÓNICA Y DISCUSIÓN}

Las edades U-Pb obtenidas en rocas del basamento estudiado, en su totalidad provenientes del análisis de circones de rocas de protolito ígneo, se consideran edades de cristalización magmática y por lo tanto estrechamente relacionadas con el emplazamiento de los cuerpos ígneos datados. Se destaca que no se han obtenido edades del Proterozoico, como lo sugerían anteriores determinaciones $\mathrm{Rb}-\mathrm{Sr}$ y $\mathrm{K}$-Ar. El rango de edades $\mathrm{U}-\mathrm{Pb}$ determinadas en rocas de basamento va de 419 Ma a 270 Ma (Tabla 4). Del total de datos, se puede distinguir un conjunto con edades entre $420 \mathrm{Ma} \mathrm{y}$ $350 \mathrm{Ma}$ (Devónico) y otro con edades entre $320 \mathrm{Ma}$ y 270 Ma (Carbonífero-Pérmico; predominantemente Pérmico inferior).

Al primer conjunto (Devónico), pertenecen las migmatitas del Complejo Colohuincul, Ios granitoides de la Tonalita San Martín de los Andes y rocas graníticas foliadas del Río Collon Curá. Las edades obtenidas en circones de tonalitas, granodioritas y granitos son próximas a $400 \mathrm{Ma}$, y de alrededor de $385 \mathrm{Ma}$ la edad de circones de venas deformadas de leucogranito alojadas en esquistos. El pico metamórfico en esas rocas se ubica próximo a $360 \mathrm{Ma}$, de acuerdo con la edad de titanita de una metadiorita de Sañicó y edades K-Ar en biotita de 370 a $310 \mathrm{Ma}$. Los afloramientos de este conjunto están en la región norte (Fig. 6 y Tabla 4). Resultados similares para la ubicación del pico de metamorfismo han obtenido Lucassen et al. (2004) en titanita de metasedimentos calcosilicáticos

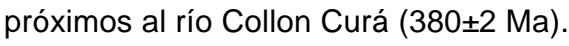

El segundo conjunto (predominantemente Pérmico inferior) tiene afloramientos en la región central-sur y esta formado por migmatitas, granodioritas, tonalitas y granitos que han sido asignados a la Formación Mamil Choique. Las edades de cristalización de estos intrusivos son de alrededor de 280 Ma y la de venas de leucogranito, relacionadas con el metamorfismo de la Formación Cushamen, próximas a 300 Ma. Las edades K-Ar en micas de estas rocas tienen valores de $275 \mathrm{Ma}$ a 250 Ma (Fig. 6 y Tabla 4).

En rocas de basamento de la zona Bariloche, la edad de $321 \mathrm{Ma}$ en circones de anfibolitas de Cañadón de la Mosca estaría fuera de los dos conjuntos mencionados y requiere en el futuro de un estudio más detallado para esclarecer su significado geológico. En cuanto a la edad de $226 \mathrm{Ma}$ obtenida en circones de granodiorita de Lago Gutiérrez, esta de acuerdo con la información de campo y corresponde a un plutón intrusivo en las rocas de basamento posteriormente a su consolidación.

Efectos de rejuvenecimiento en edades $\mathrm{K}$-Ar de minerales de rocas de basamento, debido a calentamientos que provocaron apertura del sistema isotópico, son notorios en biotita de muestras de esquistos de la Formación Cushamen aflorantes en Cañadón Angostura de Río Chico (187 Ma y 169 Ma) y en muscovita de esquistos de Lago Gutiérrez (230 y $205 \mathrm{Ma}$ ). En el primer caso puede relacionarse con el magmatismo jurásico que en la sierra de Mamil Choique consiste en un enjambre de diques de composición básica a intermedia y edad K-Ar próxima a 170 Ma (López de Luchi y Rapalini, 2002). En los esquistos de Lago Gutiérrez el calentamiento puede estar vinculado con la intrusión de granodiorita, para la que en este trabajo se brinda la edad U-Pb en circones de 226 $\pm 17 \mathrm{Ma}$.

Las edades modelo Sm-Nd $\mathrm{T}_{\mathrm{DM}}$, obtenidas en rocas basamentales de protolito ígneo, no muestran gran diferencia entre las regiones norte y central-sur. Cubren el rango entre 1.165 Ma y 1.907 $\mathrm{Ma}$ (con valores más frecuentes entre $1.387 \mathrm{Ma}$ y $1165 \mathrm{Ma})$ y $\varepsilon \mathrm{Nd}_{(\mathrm{T} 1)}$ mayoritariamente entre-3,0y-8,4. Cabe notar la importante diferencia entre las edades Sm-Nd modelo $T_{D M}$ (diferenciación manto-corteza; en el entorno 1900-1200 Ma; Paleoproterozoico tardío-Mesoproterozoico) y las correspondientes edades $\mathrm{U}-\mathrm{Pb}$ de rocas del basamento estudiado (cristalización de rocas ígneas; valores entre 420 y $270 \mathrm{Ma}$; Paleozoico, Devónico-Pérmico inferior). No hay mayores evidencias de corteza juvenil Chánica o Gondwánica, por lo que las rocas de protolito ígneo estudiadas provendrían casi enteramente de corteza mesoproterozoica reciclada, quizás en algunos casos con menor participación de materiales juveniles mantélicos. También, puede señalarse que estas edades modelo son diferentes de las observadas en dominios precámbricos del Escudo Brasileño, donde predominan edades modelo paleoproterozoicas y arqueanas (Cordani y Sato, 1999). Por otra parte, de acuerdo con la 


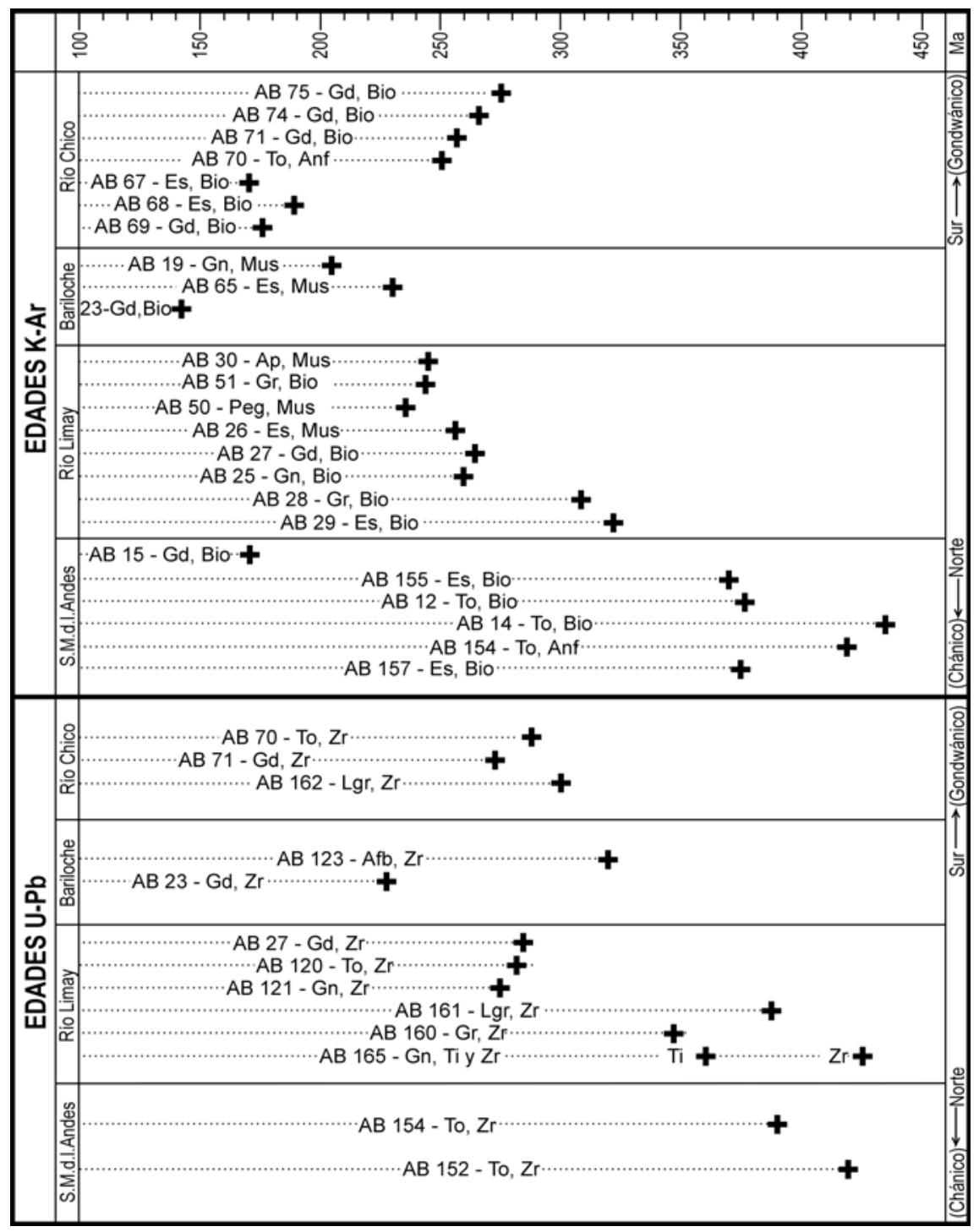

FIG. 6. Representación de resultados obtenidos por los métodos U-Pb y K-Ar. Se destaca en la región Norte edades devónicas posibles de relacionar con los Movimientos Chánicos y en la región Central-Sur edades mayormente del Pérmico (Ciclo Gondwánico). AB75, AB74, etc., muestras datadas; Gd- granodiorita; To- tonalita; Es- esquisto; Gn gneis; Ap- aplita; Gr-granito; Peg- pegmatita; Lgr- leucogranito; Afb- anfibolita; Bio- biotita; Anf- anfíbola; Mus- muscovita; Zr- circón; Ti- titanita.

composición isotópica de $\mathrm{Nd}, \mathrm{Sr}$ y $\mathrm{Pb}$, Lucassen et al. (2004) interpretaron que en el segmento andino $36^{\circ} \mathrm{S}-41^{\circ} \mathrm{S}$ y durante el Paleozoico a Triásico hubo esencialmente reciclado de corteza proterozoica, con poca adición de materiales juveniles.

Se interpreta que los dos conjuntos de edades $\mathrm{U}-\mathrm{Pb}$ obtenidas en rocas del basamento estudiado (Devónico y Carbonífero-Pérmico inferior) están relacionados con la acción de diferentes eventos tectono magmáticos (Fig. 6). El más antiguo puede correlacionarse con los Movimientos Chánicos (Azcuy et al., 1999) y con las edades radiométricas devónicas del Bloque de San Rafael (Tickyj et al., 2001), de Precordillera Occidental (Buggisch et al., 1993; Davis et al., 1999) y de Sierras Pampeanas Occidentales (Varela et al., 2002), entre otras. El conjunto más moderno cabe dentro de los límites del Ciclo Gondwánico. 
TABLA 4. SÍNTESIS DE EDADES U-Pb Y Sm-Nd OBTENIDAS, DESTACANDO LA DIFERENCIA ENTRE REGIÓN NORTE Y REGIÓN CENTRAL-SUR.

\begin{tabular}{|c|c|c|c|c|}
\hline Muestra & Localidad & Roca & $\begin{array}{l}\text { Edad U-Pb } \\
\text { (Ma) }\end{array}$ & $\begin{array}{l}\text { Edad modelo } \\
\mathrm{T}_{\mathrm{DM}} / \varepsilon \mathrm{Nd}_{(\mathrm{TI})} \\
(\mathrm{Ma})\end{array}$ \\
\hline \multicolumn{5}{|c|}{ Región Norte (Dominio Cordillerano) } \\
\hline AB 152 & San Martín de los Andes & Tonalita & $419 \pm 27$ & $1284 /(-2,97)$ \\
\hline AB 154 & Cerro Curruhuinca & Tonalita & $390,0 \pm 4,8$ & $1268 /(-4,16)$ \\
\hline AB $161 \mathrm{~A}$ & Ruta 237, al norte del río Collon Curá & $\begin{array}{l}\text { Leucogranito; } \\
\text { filones deformados } \\
\text { en esquistos }\end{array}$ & $386,6 \pm 5,4$ & - \\
\hline AB 165 A y $B$ & Oeste de Sañicó & $\begin{array}{l}\text { Gneis tonalítico; } \\
\text { metadiorita }\end{array}$ & $\begin{array}{l}\mathrm{Zr} 425 \pm 28 \\
\mathrm{Ti} \sim 360\end{array}$ & $\begin{array}{l}1567 /(-6,37) \\
1907 /(-8,40)\end{array}$ \\
\hline AB $160 \mathrm{~A}$ & Ruta 237 y Río Collon Curá & Granito & $348 \pm 11$ & - \\
\hline AB 123 & Cañadón de la Mosca & Anfibolita & $320,7 \pm 2,1$ & $1342 /(-0,59)$ \\
\hline AB 23 & Lago Gutiérrez & Granodiorita & $226 \pm 17$ & $1186 /(-5,16)$ \\
\hline \multicolumn{5}{|c|}{ Región Central y Sur (Dominio Macizo Norpatagónico) } \\
\hline AB 27 & Comallo & Granodiorita & $281 \pm 17$ & $1387 /(-7,01)$ \\
\hline AB 120 & Loma Miranda & Tonalita & $279 \pm 18$ & $1165 /(-4,98)$ \\
\hline AB 121 & Paso Flores & Gneis tonalítico & $273,1 \pm 9,5$ & - \\
\hline AB 70 & Río Chico & Tonalita & $286 \pm 13$ & - \\
\hline AB 71/91RC26 & Mamil Choique & Granodiorita & $272,4 \pm 2,2$ & $1322 /(-3,30)$ \\
\hline AB 162 B & $\begin{array}{l}\text { Río Chico, Cañadón } \\
\text { Chacay Huarruca }\end{array}$ & $\begin{array}{l}\text { Leucogranito; } \\
\text { filones deformados } \\
\text { en esquistos }\end{array}$ & $302 \pm 39$ & - \\
\hline
\end{tabular}

En este trabajo se refuerza la interpretación sugerida por Varela et al. (1999) y Basei et al. (1999), que al dar a conocer edades radiométricas del Carbonífero superior-Pérmico inferior para rocas de las zonas Comallo-Paso Flores y Bariloche, las vincularon con actividad de arco magmático. Cabe también mencionar las conclusiones del estudio petrológico de Cerredo y López de Luchi (1998), que consideraron el emplazamiento de tonalitas y granodioritas de la Formación Mamil Choique (magmatismo calcoalcalino, metaaluminoso-peraluminoso) en ambiente tectónico de arco volcánico. Además de las edades radiométricas y del carácter composicional de las rocas de protolito ígneo, los valores de $\varepsilon N d$ son moderadamente negativos, sugiriendo que los protolitos de las rocas analizadas no tenían una larga residencia cortical y una probable contribución mantélica al origen de los granitoides menos evolucionados (tonalitas y granodioritas). Valores de $\varepsilon \mathrm{Nd}_{(0)}$ en el intervalo -2 a -9, que caracterizan al presente conjunto, son comunes en granitoides generados en ambiente de arco magmático.

En la región oriental del Macizo Norpatagónico
Llambías et al. (2002) basados en estudios del Complejo Yaminué (67040'W) destacaron una importante actividad magmática neopaleozoica en el sudeste de provincia de La Pampa y norte de la provincia de Río Negro y la coherencia con las propuestas del arco de los Gondwánides (Keidel, 1916), cinturón orogénico de Samfrau (Du Toit, 1937) y cinturón móvil Mendocino-Pampeano (Criado Roque, 1972).

A nivel regional cabe hacer el siguiente análisis del significado del término basamento y las diferentes edades determinadas en el mismo. En el bosquejo de la figura 1, el basamento de las Sierras Australes de Buenos Aires, Bloque de Chadileuvú (Tickyj et al., 2002) y Sierra Grande hasta Valcheta, estaba consolidado hacia fines del Ordovícico. La relación del mismo con afloramientos de basamento de posición más occidental se ha conservado solamente en el norte patagónico. Desde el meridiano de Nahuel Niyeu al oeste tienen desarrollo las unidades ígneas y metamórficas correspondientes al Complejo Yaminué, formaciones Cushamen, Mamil Choique y Complejos Eruptivos de La Esperanza y Dos Lomas, integrantes de una corteza 
consolidada a fines del Paleozoico hasta Triásico inferior. La relación entre ambos conjuntos es tectónica, con corrimiento del Complejo Yaminué sobre el basamento de mayor antigüedad (Chernicoff y Caminos, 1996).

Las determinaciones U-Pb SHRIMP de Pankhurst et al. (2001) para rocas granìticas de Colán Conhué (Chubut), con un valor de $396 \pm 7 \mathrm{Ma}$, permiten sugerir una continuidad o la existencia de remanentes de rocas metamórficas y magmáticas de un cinturón orogénico Chánico, desde el sur de Mendoza y Neuquén hasta Chubut. Posteriormente, durante el Carbonífero y Pérmico inferior (Gondwánides), se tuvo en el borde gondwánico un escenario de margen activo con subducción, que originó la instalación de un magmatismo de arco (Bariloche, Comallo, Río Limay, Río Chico, Yaminué), metamorfismo y deformación de sedimentos con anatexis y migmatización (Complejo Yaminué, formaciones Cushamen y Mamil Choique) y probables sedimentitas de antearco (Grupos Tepuel y Genoa; Márquez et al., 2002).

En dirección norte y oeste de la región estudiada, tanto en Argentina como en Chile (Fig. 1), hay afloramientos de rocas ígneas y metamórficas que fueron datadas en el lapso Paleozoico SuperiorTriásico. En las proximidades de Aluminé cabe mencionar a las Ectinitas de la Piedra Santa, intruidas por dioritas, granodioritas y granitos de la Formación Huechulafquén (= Complejo Plutónico del Chachil). Los granitoides tienen edad K-Ar de $281 \pm 4 \mathrm{Ma}$ y $\mathrm{Rb}-\mathrm{Sr}$ de $285 \pm 5 \mathrm{Ma}$ y han sido correlacionados con los expuestos en Chile en La Región de Los lagos Ranco y Riñihue (Varela et al., 1994; Lucassen et al., 2004, y referencias allí contenidas). En Chile y a esta latitud, los mayores afloramientos neopaleozoicos están en la Cordillera de la Costa, integrando un complejo de subducción con turbiditas-metaturbiditas, metabasaltos almohadillados, 'metacherts', rocas ultramáficas serpentinizadas y 'melánges', intruido por granitoides con edades Rb-Sr entre $330 \mathrm{Ma}$ y $290 \mathrm{Ma}$ (Hervé, 1988). Un detallado estudio entre los $39^{\circ} 30^{\prime} S$ y $42^{\circ} 00^{\prime} S$ establece que el conjunto, denominado Complejo Metamórfico Bahía Mansa, habría evolucionado en el borde suroccidental de Gondwana desde el Devónico al Triásico (Duhart et al., 2001).

\section{CONCLUSIONES}

- En el noroeste patagónico no se ha comprobado con nuevos datos radiométricos, edades geológicas correspondientes al Proterozoico.

- En los afloramientos de basamento del tramo norte de la Cordillera Norpatagónica, Zona San Martín de los Andes y Río Collon Curá, en rocas correlacionables con las de las formaciones Colohuincul y Huechulafquén, se han obtenido en circones de tonalitas y granitos deformados edades $\mathrm{U}-\mathrm{Pb}$ de $420 \mathrm{Ma}$ a $380 \mathrm{Ma}$. Para esas mismas rocas las edades K-Ar en biotita van de $375 \mathrm{Ma}$ a $310 \mathrm{Ma}$. La actividad tectono magmática puede tentativamente relacionarse con los Movimientos Chánicos del oeste de la Precordillera y Cordillera Frontal, en San Juan y Mendoza. La zona denota haberse estabilizado tectónicamente hacia fines del Devónico.

- En los afloramientos de basamento de Paso Flores-Comallo y Río Chico a Cushamen, en rocas asignables a la Formación Mamil Choique, se obtuvieron edades en circones de alrededor de $280 \mathrm{Ma}$, que ubican el emplazamiento de granitoides en el
Pérmico inferior. Las edades de enfriamiento para esas rocas y metasedimentos de caja (K-Ar en micas), son próximas a 260-250 Ma, indicando su exhumación en el Pérmico superior. Las rocas del Complejo Yaminué, en la zona oriental del Macizo Norpatagónico, entendemos que son parte del mismo cinturón orogénico. Se puede relacionar con el cinturón Gondwánico (Gondwánides de Keidel, 1916), expuesto desde la Cordillera Frontal en La Rioja, San Juan y Mendoza, el Bloque de San Rafael en el sur de Mendoza y Macizo Norpatagónico (hasta los afloramientos de Yaminué por el este). - Se enfatiza que gran parte de los granitoides que componen el basamento del Macizo y Cordillera Norpatagónicos se han generado en ambiente de arco magmático, implicando subducción, en por lo menos, dos episodios principales separados por cerca de $100 \mathrm{Ma}$. El más antiguo, en la región noroccidental, tiene edad devónica (390 $\pm 30 \mathrm{Ma}$ ) y el segundo, suroriental, tuvo su climax en el Pérmico inferior $(280 \pm 10 \mathrm{Ma})$. 


\section{AGRADECIMIENTOS}

Los trabajos fueron financiados por CONICET (Argentina) y CNPq (Brasil). Durante el desarrollo de los mismos se utilizaron imágenes satelitales facilitadas por la Comisión Nacional de Actividades Espaciales (CONAE, Argentina) para el Proyecto 'Investigaciones Geológicas en el Centro-Oeste de Argentina'. Los autores agradecen la participación en alguna de las etapas del Proyecto, de los colegas W. Teixeira y B.B. Brito Neves (Universidad de
San Pablo, Brasil), A.M. Sato, P.D. González y E.J. Llambías (Universidad Nacional de La Plata). Cabe agregar que las observaciones y sugerencias de los evaluadores Dr. R.J. Pankhurst (British Antarctic Survey, Inglaterra), Dr. F. Hervé (Universidad de Chile) y Dr. M. Márquez (Universidad de la Patagonia San Juan Bosco) han mejorado la presentación original.

\section{REFERENCIAS}

Amaral, G.; Cordani, U.G.; Kawashita, K.; Reynolds, J.H. 1966. Potassium-argon dates of basaltic rocks from Southern Brazil. Geochimica et Cosmochimica Acta 30: 159-189.

Azcuy, C.L.; Carrizo, H.A.; Caminos, R. 1999. Carbonífero y Pérmico de las Sierras Pampeanas, Famatina, Precordillera, Cordillera Frontal y Bloque de San Rafael. In Geología Argentina (Caminos, R.; editor). Servicio Geológico Minero Argentino, Anales 29: 261318. Buenos Aires.

Basei, M.A.S.; Siga Jr., O.; Sato, K.; Sproesser, W.M. 1995. A instalação da metodologia U-Pb na Universidade de São Paulo. Princípios metodológicos, aplicações e resultados obtidos. Academia Brasileira de Ciencias, Anais 67: 221-237.

Basei, M.A.S.; Brito Neves, B.B.; Varela, R.; Teixeira, W.; Siga Jr.,O.; Sato, A.M.; Cingolani, C. 1999. Isotopic dating on the crystalline basement rocks of the Bariloche region, Río Negro, Argentina. In South American Symposium on Isotope Geology, No. 2, Servicio Geológico Minero Argentino, Anales 34: 1518. Buenos Aires.

Buggisch, W.; Von Gosen, W.; Henjes-Kunst, F.; Krumm, S. 1993. The age of Early Paleozoic deformation and metamorphism in the Argentine Precordillera-Evidence from K-Ar data. Zentralblatt für Geologie und Paläontologie 1 (1-2): 275-286.

Cagnoni, M.C.; Linares, E.; Haller, M.J.; Ostera, H.A. 1997. Caracterización geoquímica de la Formación Cushamen en el área de Río Chico, provincia de Río Negro, Argentina. Proveniencia y marco tectónico. In Congreso Geológico Chileno (8), Actas 2: 1229-1235. Antofagasta

Cerredo, M.E.; López de Luchi, M.G. 1998. Mamil Choique Granitoids, southwestern North Patagonian Massif, Argentina: magmatism and metamorphism associated with a polyphasic evolution. Journal of South American Earth Sciences 11 (5): 499-515.
Cerredo, M.E.; López de Luchi, M.G. 1999. Metavolcanic rocks within the metamorphic series of Cushamen Formation, North Patagonian Massif. In Congreso Geológico Argentino (14), Actas 2: 137-139. Buenos Aires.

Chernicoff, C.J.; Caminos, R. 1996. Estructura y relaciones estratigráficas de la Formación Nahuel Niyeu, Macizo Nordpatagónico oriental, Provincia de Río Negro. Revista de la Asociación Geológica Argentina 51 (3): 201-212.

Cordani, U.G.; Sato, K. 1999. Crustal evolution of the South American Platform, based on Nd isotopic systematics on granitoid rocks. Episodes 22 (3): 167173.

Criado Roque, P. 1972. Cinturón Móvil MendocinoPampeano. In Geología Regional Argentina (Leanza A.F.; editor). Academia Nacional de Ciencias: 297303. Córdoba.

Dalla Salda, L.; Cingolani, C.; Varela, R. 1991 a. El basamento pre-andino ígneo metamórfico de San Martín de los Andes, Neuquen. Revista de la Asociación Geológica Argentina 46 (3-4): 223-234.

Dalla Salda, L.H.; Cingolani, C.A.; Varela, R. 1991 b. El basamento cristalino de la región norpatagónica de los Lagos Gutiérrez, Mascardi y Guillelmo, Provincia de Río Negro. Revista de la Asociación Geológica Argentina 46 (3-4): 263-276.

Dalla Salda, L.H.; Varela, R.; Cingolani, C.; Aragón, E. 1994. The Rio Chico Paleozoic Crystalline Complex and the evolution of Northern Patagonia. Journal of South American Earth Sciences 7 (3-4): 377-386.

Davis,J.; Roeske, S.; McClelland, W.; Snee, L. 1999. Clossing the ocean between the Precordillera terrane and Chilenia: Early Devonian ophiolite emplacement and deformation in the Southwest Precordillera. In Laurentia-Gondwana connections before Pangea (Ramos, V.A.; Keppie, J.D.; editors). Geological Society of America, Special Paper 336: 115-138. 
DePaolo, D.J. 1981. Neodymium isotopes in the Colorado Front Range and crust-mantle evolution in the Proterozoic. Nature 291: 193-196.

DePaolo, D.J.; Linn, A.M.; Schubert, G. 1991. The continental crustal age distribution: methods of determining mantle separation ages from $\mathrm{Sm}-\mathrm{Nd}$ isotopic data and application to the Southwestern United States. Journal of Geophysical Research 96: 2071-2088.

Dirección Nacional del Servicio Geológico. 1994. Mapa geológico de la provincia de Río Negro, República Argentina. Dirección Nacional del Servicio Geológico, escala 1:750.000. Buenos Aires.

Duhart, P.; McDonough, M.; Muñoz, J.; Martin, M.; Villeneuve, M. 2001. El Complejo Metamórfico Bahía Mansa en la cordillera de la Costa del centro-sur de

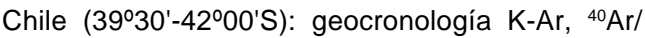
${ }^{39} \mathrm{Ary} \mathrm{U}-\mathrm{Pb}$ e implicancias en la evolución del margen sur-occidental de Gondwana. Revista Geológica de Chile 28 (2): 179-208.

Duhart, P.; Haller, M.; Hervé, F. 2002. Diamictitas como parte del protolito de las metamorfitas de la Formación Cushamen en Río Chico, provincias de Río Negro y Chubut, Argentina. In Congreso Geológico Argentino, No. 15, Actas 2: 97-100. Buenos Aires.

Du Toit, A.L. 1937. Our wandering continents. Oliver and Boyd: 366 p. Edinburgh.

Feruglio, E. 1947. Hoja 40b- San Carlos de Bariloche. Carta Geológico-Económica de la República Argentina (sin texto). Dirección General de Minas y Geología. Buenos Aires.

Galli, C.A. 1969. Descripción geológica de la Hoja 38c, Piedra del Aguila. Dirección Nacional de Geología y Minería, Boletín (111): 67 p. Buenos Aires.

Gradstein, F.M.; Ogg, J. 1996. A Phanerozoic time scale. Episodes 19: 3-5.

Hervé, F. 1988. Late Paleozoic subduction and accretion in Southern Chile. Episodes 11 (3): 183-188.

Keidel, J. 1916. La geología de las sierras de la provincia de Buenos Aires y sus relaciones con las montañas de Sud Africa y los Andes. Dirección General de Minas, Geología e Hidrología, Anales 9 (3): 78 p. Buenos Aires.

Kokogian, D.A.; Spalletti, L.; Morel, E.; Artabe, A.; Martínez, R.N.; Alcober, O.A.; Milana, J.P.; Zavattieri, A.M.; Papú, O.H. 1999. Los depósitos continentales triásicos. In Geología Argentina (Caminos, R.; editor). Servicio Geológico Minero Argentino, Anales 29: 377-398. Buenos Aires.

Linares, E.; Cagnoni, M.C.; Do Campo, M.; Ostera, H.A. 1988. Geochronology of metamorphic and eruptive rocks of southeastern Neuquén and northwestern Río Negro Provinces, Argentine Republic. Journal of South American Earth Sciences 1 (1): 53-61.

Linares, E.; Haller, M.J.; Ostera, H.A.; Cagnoni, M.C.; Galante, G. 1997. Radiometric ages of the crystalline basement of the Río Chico region, Norquinco Department, Río Negro Province, Argentina. In South
American Symposium on Isotope Geology, No. 1: 170-175. Sao Paulo.

Llambías, E.J.; Rapela, C.W. 1984. Geología de los Complejos Eruptivos de La Esperanza, provincia de Río Negro. Revista de la Asociación Geológica Argentina 39 (3-4): 220-243.

Llambías, E.J.; Varela, R.; Basei, M.; Sato, A.M. 2002. Deformación y metamorfismo Neopaleozoico en Yaminué, Macizo Norpatagónico (4050'S, 67040'W): su relación con la Fase Orogénica San Rafael y el arco de los Gondwánides. In Congreso Geológico Argentino, No. 15, Actas 3: 123-128. Buenos Aires.

López de Luchi, M.; Ostera, H.A.; Cerredo, M.E.; Linares, E.; Haller, M.J.; Cagnoni, M.C. 1999. Unravelling the ages of the crystalline basement at sierra de Mamil Choique, Río Negro, Argentine. In South American Symposium on Isotope Geology, No. 2. Servicio Geológico Minero Argentino, Anales 34: 322-326. Buenos Aires.

López de Luchi, M.G.; Ostera, H.; Cagnoni, M.; Cerredo, M.E.; Linares, E. 2002. Geodynamic setting for the western border of the Nort Patagonian Massif: Cushamen Formation at Río Chico, Río Negro. In Congreso Geológico Argentino, No.15, Actas 2: 210216. Buenos Aires.

López de Luchi, M.G.; Rapalini, A.E. 2002. Middle Jurassic dyke swarms in the North Patagonian Massif: the Lonco Trapial Formation in the sierra de Mamil Choique, Río Negro province, Argentina. Journal of South American Earth Sciences 15: 625-641.

Lucassen, F.; Trumbull, R.; Franz, G.; Creixell, C.; Vásquez, P.; Romer, R.L.; Figueroa, O. 2004. Distinguishing crustal recycling and juvenile additions at active continental margins: the Paleozoic to Recent compositional evolution of the Chilean Pacific margin (36-41ㅇ). Journal of South American Earth Sciences 17: 103-119.

Ludwig, K.R. 2002. Using Isoplot/Ex. A geochronological toolkit for Microsoft Excel. Berkeley Geochronology Center, Special Publication (1). Berkeley.

Márquez, M.; Giacosa, R.; Nillni, A.; Paredes, J.; Fernández, M.; Parisi, C.; Sciutto, J.; Garrido, C.; Afonso, J. 2002. Aspectos litológicos y estructurales del Bloque Tectónico Cushamen (Chubut). In Congreso Geológico Argentino, No. 15, Actas 1: 201-206. Buenos Aires.

Nullo, F.E. 1979. Descripción geológica de la Hoja 39c, Paso Flores. Servicio Geológico Nacional, Boletín 167: 70 p. Buenos Aires.

Ostera, H.A.; Linares, E.; Haller, M.J.; Cagnoni, M.C.; López de Luchi, M. 2001. A widespread Devonian metamorphic episode in Northern Patagonia, Argentina. In South American Symposium on Isotope Geology, No. 3, Actas, CD. Abstracts. Revista Comunicaciones 52: 161. Santiago.

Pankhurst, R.J.; Rapela, C.W.; Caminos, R.; Llambías, E.; Parica, C. 1992. A revised age for the granites of the central Somuncura Batholith, North Patagonian 
Massif. Journal of South American Earth Sciences 5 (3-4): 321-325.

Pankhurst, R.J.; Rapela, C.W.; Loske, W.P.; Fanning, C.M. 2001. Chronological study of the pre-Jurassic basement rocks of Southern Patagonia. In South American Symposium on Isotope Geology, No. 3, Actas CD. Abstracts. Revista Comunicaciones 52: 163. Santiago.

Parica, C.A. 1986. Resultados geocronológicos preliminares de las Formaciones Colohuincul y Huechulafquén, provincia de Neuquen. Revista Asociación Geológica Argentina 41 (1-2): 201-205.

Rapela, C.W.; Llambías, E.J. 1985. Evolución magmática y relaciones regionales de los Complejos Eruptivos de La Esperanza, provincia de Río Negro. Revista de la Asociación Geológica Argentina 40 (1-2): 4-25.

Rapela, C.W.; Pankhurst, R.J.; Llambías, E.J.; Labudía, C.; Artabe, A. 1996. 'Gondwana' magmatism of Patagonia: inner cordilleran calc-alkaline batholiths and bimodal volcanic provinces. International Symposium on Andean Geodinamics (3): 791-794.

Ravazzoli, I.A.; Sesana, F.L. 1977. Descripción geológica de la Hoja 41c, Río Chico. Servicio Geológico Nacional Boletín (148): 77 p. Buenos Aires.

Sato, K.; Tassinari, C.C.G.; Kawashita, K; Petronilho, L. 1995. O método geocronológico Sm-Nd no IG/USP e suas aplicaçoes. Academia Brasileira de Ciencias, Anais 67: 313-336.

Servicio Geológico Minero Argentino. 1997. Mapa geológico de la República Argentina. Servicio Geológico Minero Argentino. Buenos Aires.

Servicio Nacional de Geología y Minería. 1982. Mapa Geológico de Chile. Servicio Nacional de Geología y Minería, escala 1:1.000.000.

Steiger, R.H.; Jäger, E. 1977. Convention on the use of decay constants in geo and cosmochronology. Earth and Planetary Science Letters 36 (3): 359-362.

Tickyj, H.; Cingolani, C.; Varela, R.; Chemale Jr., F. 2001. $\mathrm{Rb}-\mathrm{Sr}$ ages from La Horqueta Formation, San Rafael
Block, Argentina. In South American Symposium on Isotope Geology, No. 3, Actas, CD Abstracts. Revista Comunicaciones 52: 168. Santiago.

Tickyj, H.; Llambías, E.J.; Melchor, R.N. 2002. Ordovician rocks from La Pampa province, Argentina. In Aspects of the Ordovician System in Argentina (Aceñolaza, F.G.; editor). Instituto Superior de Correlación Geológica, Serie Correlación Geológica (16): 257266. Tucumán.

Turner, J.C.M. 1973. Descripción geológica de la Hoja 37 a, b, Junín de los Andes. Servicio Nacional Minero Geológico, Boletín (138): 86 p. Buenos Aires.

Varela, R.; Dalla Salda, L.; Cingolani C.; Gómez, V. 1991. Estructura, petrología y geocronología del basamento de la región del Limay, provincias de Río Negro y Neuquen, Argentina. Revista Geológica de Chile,18 (2): 147-163.

Varela, R.; Teixeira, W.; Cingolani, C.; Dalla Salda, L. 1994. Edad Rubidio-Estroncio de granitoides de Aluminé-Rahue, Cordillera Norpatagónica, Neuquén, Argentina. In Congreso Geológico Chileno, No. 7, Actas 2: 1254-1258. Concepción.

Varela, R.; Basei, M.A.S.; Brito Neves, B.B.; Sato, A.M.; Teixeira, W.; Cingolani, C.A.; Siga Jr., O. 1999. Isotopic study of igneous and metamorphic rocks of ComalloPaso Flores, Río Negro, Argentina. In South American Symposium on Isotope Geology (2) .Servicio Geológico Minero Argentino, Anales 34: 148-151. Buenos Aires.

Varela, R.; Sato, A.M.; González, P.D. 2002. Metamorfismo y deformación devónicos en la sierra de Umango, Sierras Pampeanas Occidentales, La Rioja, Argentina. In Congreso Geológico Argentino, No. 15, Actas 2: 57-63. Buenos Aires.

Volkheimer, W. 1964. Estratigrafía de la zona extraandina del Departamento de Cushamen (Chubut). Revista de la Asociación Geológica Argentina 19 (2): 85-107.

Volkheimer, W.; Lage, J. 1981. Descripción geológica de la Hoja 42c, Cerro Mirador. Servicio Geológico Nacional Boletín (181): 71 p. Buenos Aires 